\title{
RESEARCH
}

Open Access

\section{Healthcare-seeking behavior among pregnant women in the Chinese hierarchical medical system: a cross- sectional study}

Guihao Liu ${ }^{1,2+}$, Yunlian Xue ${ }^{1 \dagger}$, Zhenzhu Qian ${ }^{4}$, Liuna Yang ${ }^{4}$, Yunbin Yang ${ }^{2,4^{*}}$, Qingshan Geng ${ }^{1 *}$ and Xin Wang ${ }^{3^{*}}$

\author{
Abstract \\ Background: Hierarchical medical systems are common in developed countries, but it's not optimistic in China. \\ This study aimed to identify the factors affecting healthcare-seeking behavior among pregnant women in \\ Guangdong, China.
}

Methods: We conducted a cross-sectional, observational survey, developed using the Andersen's behavioral model. Pregnant women were randomly selected using a two-stage, stratified, random sampling method from hospitals in Guangdong, China. A multinomial logistic regression was used to identify statistically significant variables from aspect of environmental, demographic and pregnancy characteristics associated with pregnant women seeking healthcare at primary, secondary or tertiary hospitals.

Results: A total of 1393 pregnant women returned the survey after attending 1 of 12 hospitals within 4 cities of the Guangdong province: 537 (38.5\%) of the respondents attended a primary hospital, 437 (31.4\%) a secondary hospital, and 419 (30.1\%) a tertiary hospital. Women attending primary hospitals were more likely to live closer to the hospital, live rurally, and be educated to a lower level. Several factors were significantly associated with attendance at a secondary vs a primary hospital: the woman's perceived necessity to seek maternal healthcare (OR $1.73,95 \% \mathrm{Cl}[1.1,2.74])$, the woman's choice of delivery hospital (OR 1.45, 95\% Cl [1.01,2.07]), or urban living (OR 1.39, $95 \% \mathrm{Cl}[1.03,1.88])$. Characteristics associated with attendance at a tertiary vs a primary hospital were: a history of pregnancy complications (OR 2.35, 95\% Cl [1.43,3.86]), travel to the hospital by public transport/taxi (OR 2.09/2.67, 95\% Cl $[1.35,3.22] /[1.45,4.92])$, urban living (OR 1.58, 95\% Cl [1.14,2.18]), or a planned current pregnancy (OR 1.53, $95 \%$ Cl $[1.07,2.19])$.

Conclusion: Medical needs and convenience both play a role in the choice of hospital for antenatal care, and impact on equity utilization of health services. Pregnant women without risk factors and with higher levels of education should be a target population for guiding to choose a more proper level of hospital.

Keywords: Hierarchical medical system, Pregnant women, Environmental factors, Demographic factors, Antenatal care

\footnotetext{
*Correspondence: yyb08@126.com; gengqingshan@gdph.org.cn; wxinsmile@qq.com

${ }^{\dagger}$ Guihao Liu and Yunlian Xue contributed equally to this work.

${ }^{2}$ Southern Medical University, 1023-1063 Shatai south road, Guangzhou, Guangdong, China

'Guangdong Provincial People's Hospital, Guangdong Academy of Medical Sciences, 106 Zhongshan II Yuexiu District, Guangzhou, Guangdong, China

${ }^{3}$ College of Humanities and Social Sciences, China Medical University, 77

Puhe Road, Shenbei New District, Shenyang, Liaoning, China

Full list of author information is available at the end of the article
}

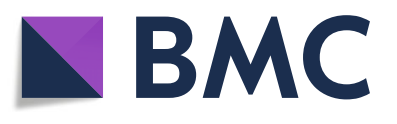

(c) The Author(s). 2019 Open Access This article is distributed under the terms of the Creative Commons Attribution 4.0 International License (http://creativecommons.org/licenses/by/4.0/), which permits unrestricted use, distribution, and reproduction in any medium, provided you give appropriate credit to the original author(s) and the source, provide a link to the Creative Commons license, and indicate if changes were made. The Creative Commons Public Domain Dedication waiver (http://creativecommons.org/publicdomain/zero/1.0/) applies to the data made available in this article, unless otherwise stated. 


\section{Background}

The maternal mortality rate is widely used to assess the quality of obstetric care in different countries and regions [1]. Over the last decade, the maternal mortality rate has dropped significantly in China, from 80 per hundred thousand in 1991, to 21.7 per hundred thousand in 2014 [2]. Comprehensive maternal care is vital in assuring the safety, and well-being women and their newborn children [3]. However, the under-utilized maternal healthcare services in China have affected the equity in utilization of health services. Seeking healthcare advice as a preventative method is the ideal way to reduce the risks of pregnancy for both the mother and unborn child. This type of healthcare service is generally high throughput in nature and attracts minimal investment, despite its great importance in promoting maternal and child health [4].

Healthcare-seeking behaviour can be understood as a person's process of engaging (or not) with a particular health service. This includes aspects such as how symptoms are perceived and acted upon and how, as well as which type of and when, healthcare services are accessed [5]. Healthcare-seeking behavior has emerged as a tool to tackle perceived ill health by taking remedial actions [6]. A woman's decision to seek healthcare is not an isolated event; rather, it is a composite result of her personal needs, social forces, actions of healthcare providers, and the location of services [7]. Andersen's health behavior model systematically explores the factors which influence health service utilization [8]. The model includes four main parts: environmental factors, population characteristics, health behaviors, and health outcomes [9]. At its core, the model suggests that a person's individual characteristics and healthcare needs influence their motivation and ability to access healthcare services; therefore, overall health service utilization is affected by population characteristics and their environment [10, 11]. Andersen's model has been widely used in many fields, but particularly by healthcare decision makers, who use it to optimize health service utilization [12].

Chinese Hierarchical Medical System contains threelevel medical institutions, primary, secondary and tertiary medical institutions. Compared with primary and secondary medical institutions, tertiary medical institutions have more experienced experts and advanced equipments. As a result, the actual demands may be ignored and patients tends to see doctors in the tertiary medical institution. This could aggravate the inequity of health seeking. Pregnant women usually have insufficient knowledge of pregnant symptoms [13]. It has been indicated that the equity of maternal and child health service utilization in China was improved from 2010 to 2015; however, economically developed areas and eastern areas were relatively concentrated on in this study [14]. Guangdong Province is in southern east of China and one of the most population provinces. After the promulgation of the comprehensive "two-child" policy, the number of pregnant women has increased markedly, which leads to a bigger challenge for equity of healthcare-seeking. Our previous studies indicated that the passing rate $(71.4 \%)$ of healthcare seeking behavior of puerpera in Guangdong Province was low, and many factors influenced the healthcare-seeking behavior [15].

Although, some large studies have evaluated the environmental and demographic factors affecting healthcareseeking behavior of pregnant women in developed countries [16-18], only a few studies in China have been found [19]. Due to the great demand of health service providing of gynaecology and obstetrics especially after the promulgation of the comprehensive "two-child" policy, it is important to promote an equitable and reasonable healthcare-seeking environment for pregnant women. This study aimed to discover the factors influencing healthcare-seeking behavior of pregnant women in Guangdong hierarchical healthcare system and put forward feasible measures to improve the equity of healthcare-seeking behavior of pregnant women.

\section{Methods}

\section{Study setting and sampling}

A cross-sectional survey conducted in hospitals around of Guangdong province in China. The study protocol was approved by the Guangdong Provincial People's Hospital. Institutional Review Board and followed principle expressed in the Declaration of Helsinki. Pregnant women were recruited in a two-stage stratified sampling process. In the first stage, Guangzhou (middle area, 13.50 million population), Foshan (middle area, 7.43 million population), Shaoguan (north area, 2.93 million population) and Zhanjiang (west area, 7.24 million population) were selected. In terms of the aspect of areas division, Guangzhou and Foshan are in the middle area, Shaoguan is in the north area, Zhanjiang is in the west area. With regards to the population scale in 2015, the populations are 13.50 million, 7.43 million, 7.24 million and 2.93 million in Guangzhou, Foshan, Zhanjiang and Shaoguan, respectively [20]. In addtion, based on the GDP ranking in 2015, of all the 21 cities, Guangzhou is No.1, Foshan is No.3, Zhanjiang is No.7, Shaoguan is No.16 [21]. The comprehensive consideration of area, population scale and GDP ranking indicate that these chosen cities are sufficiently represented the socioeconomic backgrounds of Guangdong Province. In the second stage, target hospitals were sampled from the selected cities, stratified by the level of specialized care available. In each city, one general hospital or maternal and child care service center was chosen from the primary, secondary, or tertiary medical institutions respectively. In total, 12 hospitals were chosen, and pregnant 
women who sought for healthcare in a particular time period in these hospitals were investigated.

\section{Respondents}

Respondents were women who had antenatal care with gestational week more than 28 at one of the selected hospitals, and get into the investigation during Apr. 2017 and Oct. 2017. Written informed consent was obtained from each respondent prior to completion of the survey. We planned to survey approximately 1500 pregnant women, equally distributed among the 12 sampled hospitals.

\section{Survey}

Surveys were developed using the Andersen's behavioral model and distributed to respondents by the doctors providing antenatal care. The survey contained 25 questions, which were selected by 24 experts in obstetrics and gynecology, epidemiology and health statistics, psychology, and health policy during two rounds of Delphi consultation. The details of establishment of comprehensive evaluation index system of maternal healthcare-seeking behavior were described in our previous study [22]. The questions formed two broad categories: 1) environmental factors that impact healthcare-seeking behaviors: urban vs rural living, annual per capita household income, knowledge of the national maternal healthcare policies, previous participation in either health education or consulting, a medical examination prior to pregnancy, a health assessment/medical guidance, or a network-based health education program; 2) population characteristics that impact healthcare-seeking behaviors: age, highest level of education, marital status, number of previous pregnancies, number of previous abortions, number of prior live births, history of pregnancy complications, whether the current pregnancy was planned, opinion on the necessity for maternal healthcare, feelings on the necessity for an antenatal examination when feeling good, whether it was in the women's power to decide on the location of delivery, health insurance schemes, distance from the hospital, mode of transport to the hospital, waiting time to see the doctor, subjective feelings about maternal healthcare, feelings on how the antenatal advice applies to their personal situation, or if personal privacy was respected during antenatal care. These questions were all contained in the single factor analysis, and only the ones had statistically significant difference were brought into multiple factors analysis.

\section{Data processing and analyses}

Surveys were completed between Apr. 2017 and Oct. 2017. Prior to the start of the study in each hospital, the local team received training on survey and data collection techniques from the research team. Questions could be misunderstood were detailed explained to respondents. Data were checked for completeness and inconsistencies, coded, and entered into Epidata 3.0. Descriptive analysis was used for the demographic characteristics of the participants. A chisquare test was used to identify variables associated with healthcare seeking at each level of hospital. Those variables with statistical significance were included in a multinomial logistic regression analysis (test of parallel lines of ordinal logistic analysis was rejected). Two-sided $p$-values $<0.05$ were considered to indicate statistical significance. All statistical analysis was done using SPSS software, version 20.0.

\section{Results}

In total, 1420 of the 1500 distributed survey were recollected. Among these, 27 were considered invalid due to incomplete data. The valid returned rate was $92.9 \%$.

\section{Demographic characteristics of the respondents}

Overall, $537(38.5 \%)$ of the respondents attended a primary hospital, 437 (31.4\%) a secondary hospital, and $419(30.1 \%)$ a tertiary hospital. The 1393 pregnant women aged from 17 to 43 years old, with a mean ( \pm standard deviation) of $28.0 \pm 4.8$ years. Only 100 respondents were aged over 35 years (7.2\%). About half (647 [46.4\%]) of the respondents had a college degree or above, while more than half (769, $55.2 \%)$ resided in a rural area of the province. The median distance to the hospital was $5 \mathrm{~km}$, but $20.6 \%$ (287) of the respondents travelled more than $10 \mathrm{~km}$. In addition, 1219 (87.5\%) respondents' subjective feelings about maternal healthcare were good, 1353 (97.1\%) respondents' subjective feeling about personal privacy were respected during antenatal care.

Among the Respondents, 725 (52.0\%) reported annual per capita household income of less than $50,000 ¥$. The majority (1207 [86.6\%]) of respondents were covered by health insurance schemes, of which medicare accounted for $56.3 \%$ (679), new rural cooperative medical system accounted for $32.3 \%$ (390), free medicare accounted for 9.7\% (117), and commercial insurance accounted for $1.7 \%$ (21). The median of waiting time to see the doctor was $20 \mathrm{~min}$; however, $20.2 \%$ (281) of the respondents waited less than $15 \mathrm{~min}$, and 18.6\% (259) more than 30 min. Notably, we found that the incidence of abortion and pregnancy complications among women aged over 35 years old were 29.9 and $17.0 \%$, higher than in younger women, respectively.

\section{Factors associated with healthcare-seeking at primary, secondary or tertiary hospitals}

Univariate chi-square test identified 14 demographic variables that were significantly different between the hospital levels. Pairwise comparisons were also done (Table 1). 
Table 1 Comparison of factors associated with pregnant women attending different primary, secondary and tertiary hospitals $(n=1393)$

\begin{tabular}{lll}
\hline Variable, $\mathrm{n}(\%)$ & Hospital level & P-value \\
\cline { 2 - 2 } & Primary Secondary Tertiary & \\
\hline
\end{tabular}

Environmental factors

Urban vs rural living

Urban

$185(34.5) \quad 216(49.4) \quad 223(53.2)<0.001$

Rural

$352(65.5) \quad 221(50.6) \quad 196(46.8)$

Annual per capita household income

$<50,000 ¥$

$317(59) \quad 245(56.8) \quad 163(39.1) \quad<0.001$

$\geq 50,000 ¥$

$220(41.0) \quad 186(43.2) \quad 254(60.9)$

Aware of the national maternal healthcare policies?

Yes

$339(63.1) \quad 296(67.7) \quad 258(61.6) \quad 0.143$

No

$198(36.9) \quad 141(32.3) \quad 161(38.4)$

Previously participated in any health education or consulting before pregnancy?

$\begin{array}{lllll}\text { Yes } & 282(52.5) & 206(47.1) & 216(51.7) & 0.215\end{array}$

Previously participated in medical examination before pregnancy?

Yes $\quad 304(56.6) \quad 280(64.1) \quad 266(63.6) \quad 0.026$

No $\quad 233(43.4) \quad 157(35.9) \quad 152(36.4)$

Previously sought a health assessment or medical guidance before pregnancy?

$\begin{array}{lllll}\text { Yes } & 193(35.9) & 125(28.6) & 134(32.1) & 0.051 \\ \text { No } & 344(64.1) & 312(71.4) & 284(67.9)\end{array}$

Previously participated in network-based health education?

\begin{tabular}{|c|c|c|c|}
\hline Yes & 109 (20.3) & 93 (21.3) & 73 (17.5) \\
\hline No & 428 (79.7) & 344 (78.7) & 345 (82.5) \\
\hline
\end{tabular}

Demographic and pregnancy characteristics

Age, years

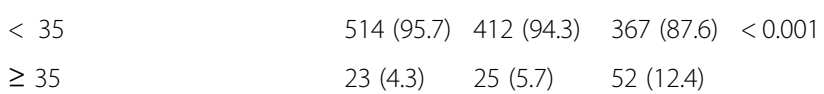

Highest education level

Junior high school or below $160(29.8) \quad 86(19.7) \quad 70(16.7) \quad<0.001$

High school

206 (38.4) $117(26.8) \quad 107(25.5)$

College or above

$171(31.8) \quad 234(53.5) \quad 242(57.8)$

Number of previous pregnancies

$\begin{array}{lllll}1 \text { time } & 309(57.5) & 281(64.3) & 223(53.2)<0.001 \\ 2 \text { times } & 132(24.6) & 123(28.1) & 114(27.2) & \\ \geq 3 \text { times } & 96(17.9) & 33(7.6) & 82(19.6) & \\ \text { Number of abortions } & & & \\ \text { None } & 361(67.2) & 324(74.1) & 272(64.9)<0.001 \\ \text { Once } & 121(22.5) & 99(22.7) & 80(19.1) \\ \geq 2 \text { times } & 55(10.2) & 14(3.2) & 67(16.0)\end{array}$

Number of prior live births

0
Table 1 Comparison of factors associated with pregnant women attending different primary, secondary and tertiary hospitals ( $n=1393$ ) (Continued)

\begin{tabular}{lllll}
\hline Variable, $n(\%)$ & \multicolumn{2}{l}{ Hospital level } & P-value \\
\cline { 2 - 4 } & Primary & Secondary & Tertiary & \\
\hline 1 & $109(20.3)$ & $68(15.6)$ & $83(19.8)$ & \\
$\geq 2$ & $10(1.9)$ & $7(1.6)$ & $9(2.1)$ & \\
History of pregnancy complications & & & \\
Yes & $37(6.9)$ & $34(7.8)$ & $75(17.9)$ & $<0.001$ \\
No & $500(93.1)$ & $402(92.2)$ & $344(82.1)$ & \\
Current pregnancy was planned & & & \\
Yes & $395(73.6)$ & $343(78.5)$ & $348(83.7)$ & 0.001 \\
No & $142(26.4)$ & $94(21.5)$ & $68(16.3)$ &
\end{tabular}

Agrees with the necessity for maternal healthcare

$\begin{array}{lllll}\text { Yes } & 460(85.7) & 405(92.7) & 359(85.9) & 0.001\end{array}$

No $\quad 77(14.3) \quad 32(7.3) \quad 59(14.1)$

Agrees with the necessity for maternal healthcare when feeling good

Yes $\quad 498(92.7) \quad 415(95.0) \quad 398(95.0) \quad 0.225$

No $\quad 39(7.3) \quad 22(5.0) \quad 21(5.0)$

Delivery location was predominantly selected by the woman

$\begin{array}{lllll}\text { Yes } & 422(78.6) & 373(85.4) & 359(85.7) & 0.004\end{array}$

No (i.e. selected by others) $115(21.4) \quad 64(14.6) \quad 60(14.3)$

Health insurance schemes

$\begin{array}{lllll}\text { Yes } & 467(87.0) & 375(85.8) & 365(87.1) & 0.824\end{array}$

No $\quad 70(13.0) \quad 62(14.2) \quad 54(12.9)$

Distance to hospital

$\begin{array}{lllll}<5 \mathrm{~km} & 219(40.8) & 189(43.3) & 143(34.2) & 0.034 \\ 5-10 \mathrm{~km} & 218(40.6) & 163(37.4) & 172(41.2) \\ >10 \mathrm{~km} & 100(18.6) & 84(19.3) & 103(24.6)\end{array}$

Mode of transport to the hospital

$\begin{array}{lllll}\text { Private cars } & 177(33.1) & 181(41.4) & 177(42.7) & <0.001\end{array}$

Public transport $\quad 172(32.1) \quad 119(27.3) \quad 144(34.7)$

Taxi

$38(7.1) \quad 26(5.9) \quad 40(9.6)$

On foot

$148(27.7) \quad 111(25.4) \quad 54(13.0)$

Waiting time to see the doctor

$<15 \min \quad 149(27.7) \quad 87(20) \quad 45(10.7) \quad<0.001$

15-30 min $\quad 323(60.1) \quad 262(60.1) \quad 267(63.8)$

31-60 min $\quad 55(10.3) \quad 77(17.7) \quad 88(21.0)$

$\begin{array}{llll}>60 \mathrm{~min} & 10(1.9) & 10(2.2) & 19(4.5)\end{array}$

Subjective feeling that the antenatal advice applies to their current situation

Yes - it does $\quad 515(95.9) \quad 417(95.4) \quad 408(98.1) \quad 0.084$

No - it does not $22(4.1) \quad 20(4.6) \quad 8(1.9)$

Note. $\mathrm{P}$ is from a chi-squared test. Age take 35 as cutoff for pregnant women aged more than 35 usually be called elderly pregnant women 
Multinomial logistic regression analysis with primary hospital as the dependent variable was performed to reveal the factors associated with attendance at each level of hospital (Table 2).

Pregnant women who attended a primary hospital were significantly more likely to have travelled 5 to $10 \mathrm{~km}$ from the hospital (vs $>10 \mathrm{~km}$ ), reside in a rural area, or have a lower education level than those attending a secondary or tertiary hospital. Pregnant women attending a primary hospital were more likely to have travelled less than $5 \mathrm{~km}$, waited less than $15 \mathrm{~min}$ to see a doctor (vs $\geq 60 \mathrm{~min}$ ), have an unplanned pregnancy, no history of a complicated pregnancy, had one previous abortion (vs $\geq 2$ ), or be aged $<35$ years, than those who attended a tertiary hospital.
Conversely, women who attended a secondary hospital vs a primary hospital were more likely to believe it necessary to seek maternal healthcare and were more likely to have made the decision on the location of the delivery themselves. Women attending a tertiary hospital vs a primary hospital were more likely to have travelled to the hospital by public transport or taxi (vs on foot).

\section{Discussion}

Andersen's health behavioral model is the cornerstone of many studies assessing patient healthcare-seeking behavior and the accessibility of health services. The model has been used to improve healthcare services worldwide $[11,12,23]$. Our results demonstrated that there were

Table 2 Multinomial logistic regression analysis of factors associated with pregnant women attending different levels of hospital in Guangdong, China $(n=1393)$

\begin{tabular}{|c|c|c|c|c|c|c|}
\hline & \multicolumn{3}{|c|}{ Secondary vs primary hospital } & \multicolumn{3}{|c|}{ Tertiary vs primary hospital } \\
\hline & $\mathrm{B}$ & $P$-value & $\mathrm{OR}[95 \% \mathrm{Cl}]$ & $\mathrm{B}$ & P-value & $\mathrm{OR}[95 \% \mathrm{Cl}]$ \\
\hline Overall & -1.551 & 0.035 & & 1.602 & 0.016 & \\
\hline \multicolumn{7}{|l|}{ Distance to hospital, vs > $10 \mathrm{~km}$} \\
\hline$<5 \mathrm{~km}$ & -0.296 & 0.148 & $0.74[0.50,1.11]$ & -0.490 & 0.022 & $0.61[0.40,0.93]$ \\
\hline $5-10 \mathrm{~km}$ & -0.419 & 0.032 & $0.66[0.45,0.96]$ & -0.474 & 0.017 & $0.62[0.42,0.92]$ \\
\hline \multicolumn{7}{|l|}{ Waiting time to see the doctor, vs $>60 \mathrm{~min}$} \\
\hline$<15 \min$ & -0.435 & 0.385 & $0.65[0.24,1.73]$ & -1.731 & $<0.001$ & $0.18[0.07,0.44]$ \\
\hline $15-30 \mathrm{~min}$ & 0.037 & 0.939 & $1.04[0.40,2.70]$ & -0.642 & 0.139 & $0.53[0.23,1.23]$ \\
\hline $31-60 \mathrm{~min}$ & 0.528 & 0.304 & $1.7[0.62,4.63]$ & -0.170 & 0.713 & $0.84[0.34,2.09]$ \\
\hline \multicolumn{7}{|l|}{ Mode of transport vs on foot } \\
\hline Private car & 0.024 & 0.900 & $1.02[0.71,1.49]$ & 0.419 & 0.059 & $1.52[0.98,2.35]$ \\
\hline Public transport & -0.117 & 0.547 & $0.89[0.61,1.3]$ & 0.735 & 0.001 & $2.09[1.35,3.22]$ \\
\hline Taxi & -0.037 & 0.904 & $0.96[0.53,1.75]$ & 0.982 & 0.002 & $2.67[1.45,4.92]$ \\
\hline Annual per capita household income, $<$ vs $\geq 50,000 ¥$ & 0.281 & 0.064 & $1.32[0.98,1.78]$ & -0.277 & 0.082 & $0.76[0.56,1.04]$ \\
\hline Urban vs rural living & 0.328 & 0.033 & $1.39[1.03,1.88]$ & 0.456 & 0.006 & $1.58[1.14,2.18]$ \\
\hline Planned pregnancy, yes vs no & 0.072 & 0.659 & $1.08[0.78,1.48]$ & 0.424 & 0.020 & $1.53[1.07,2.19]$ \\
\hline History of complicated pregnancy, yes vs no & 0.456 & 0.101 & $1.58[0.92,2.72]$ & 0.852 & 0.001 & $2.35[1.43,3.86]$ \\
\hline Necessity for maternal healthcare, yes vs no & 0.549 & 0.019 & $1.73[1.1,2.74]$ & -0.239 & 0.268 & $0.79[0.52,1.20]$ \\
\hline Previously participated in medical examination before pregnancy, yes vs no & 0.187 & 0.190 & $1.21[0.91,1.59]$ & 0.108 & 0.473 & $1.11[0.83,1.50]$ \\
\hline \multicolumn{7}{|l|}{ Number of previous pregnancies, vs $\geq 3$} \\
\hline 1 & 0.466 & 0.224 & $1.59[0.75,3.38]$ & 0.143 & 0.729 & $1.15[0.51,2.59]$ \\
\hline 2 & 0.585 & 0.070 & $1.80[0.95,3.38]$ & 0.674 & 0.058 & $1.96[0.98,3.94]$ \\
\hline \multicolumn{7}{|l|}{ Number of prior abortions, vs $\geq 2$} \\
\hline None & 0.709 & 0.140 & $2.03[0.79,5.2]$ & -0.526 & 0.239 & $0.59[0.25,1.42]$ \\
\hline 1 & 0.768 & 0.067 & $2.16[0.95,4.90]$ & -0.939 & 0.014 & $0.39[0.19,0.83]$ \\
\hline Age, $<35$ vs $\geq 35$ years & -0.351 & 0.271 & $0.70[0.38,1.32]$ & -0.975 & 0.001 & $0.38[0.21,0.68]$ \\
\hline Decision-making power of delivery, yes vs no & 0.369 & 0.043 & $1.45[1.01,2.07]$ & 0.221 & 0.254 & $1.25[0.85,1.82]$ \\
\hline \multicolumn{7}{|l|}{ Highest education level, vs college or above } \\
\hline Junior high school or below & -0.687 & 0.001 & $0.5[0.34,0.75]$ & -1.171 & $<0.001$ & $0.31[0.2,0.49]$ \\
\hline High school & -0.779 & $<0.001$ & $0.46[0.33,0.65]$ & -0.966 & $<0.001$ & $0.38[0.27,0.55]$ \\
\hline
\end{tabular}


significant demographic/pregnancy and environmental factor differences among pregnant women attending primary, secondary and tertiary hospitals.

Several of the identified factors were consistent with the known risk factors for pregnancy, indicating that the national prenatal health service in China was functioning well at the time of the survey. For example, our study showed that pregnant women of advanced maternal age (AMA) (aged 35 years or older) were more likely to be attending a tertiary hospital than a primary hospital for antenatal care. AMA is widely recognized as a risk factor for pregnancy complications and adverse pregnancy outcomes [24-26]. Although we cannot determine the reasons for each hospital visit, the finding that advanced women were attending a tertiary hospital suggests that these women were receiving more specialized care.

Health Commission of Guangdong Province released that the incidence of 'high risk pregnancies' is increasing, and significantly so, from $12 \%$ in 2013 to $30 \%$ in 2015 [27]. At the beginning of 2016, the Chinese health and family planning commission implemented a 'two-child policy', which is expected to increase the number of pregnancies and births, particularly to older mothers. The current healthcare-seeking behavior findings suggest that this may put additional demand on tertiary hospitals; thus, early assessment of all pregnant women at primary or secondary hospitals should be encouraged in order to prioritize resource allocation most effectively and promoting the equity of healthcare-seeking behavior of pregnant women.

This study indicated that tertiary hospitals were more likely to be attended by pregnant women with a history of pregnancy complications, abortion, and who were having a planned pregnancy, than a primary hospital. The former two groups of pregnant women chose the tertiary hospitals mostly out of the consideration of their actual medical needs, in line with previous studies [28]. However, for those women with planned pregnancy, seeking healthcare in the tertiary hospitals probably only because of them being cautious and attentive to the needs of the current pregnancy, rather than medical needs, this may not be encouraged from the perspective of health equity. Interestingly, a New Zealand study has shown no difference of clinical outcomes of women giving birth in either a tertiary level maternity hospital or a freestanding primary level maternity unit [29]. This paper concluded that women's experience of transfer to a primary hospital was generally positive, suggesting that patients can be reallocated between hospitals during pregnancy. For example, a patient attending a tertiary hospital could be asked to attend a primary hospital where the clinical conditions allow, freeing up specialized resources for those with the most need. For health system and standard hospital facilities are different in China, convenient reallocation are impossible in most areas currently. Thankfully, a series of policies are being carried out, which make it possible someday.

Our findings also showed women attending a secondary or tertiary hospital were more likely to reside in an urban area, or have received a higher level of education than those attending the primary hospital. These findings are similar to the earlier research of Yanikkerem et al [30]. Large differences in healthcare accessibility in urban and rural areas is commonly observed in many countries, for example the Philippines and Cambodia $[31,32]$. In the province of Guangdong, China, the distribution of tertiary hospitals favors urban areas. Half of all tertiary hospitals are located in the city of Guangzhou, whereas most other cities in the region have one or no tertiary hospitals. According to the China Statistical Yearbook, 178 township health centers and 16 community health centers in Guangdong hadn't delivered any babies during 2015, and 412 maternity beds were idle. This indicates that there is a large pool of unutilized resources in primary care locations. This study suggested that pregnant women with higher level of education were potential target for interrupting of healthcare seeking behavior.

Secondary hospitals are more likely to be attended by pregnant women who considere it necessary to seek maternal healthcare and who decide for themselves where to have their baby delivered. A study has previously suggested that spouses can intensely influence the maternal healthcare sought by a pregnant woman. Men typically are the primary earners and this often manifests as also having a strong influence in a wife's medical care [33, 34]. The influence of family in a woman's maternal healthcare is an interesting topic and deserves further study [35]. For the aspect of equity of health, assessing the health risks of pregnant women and diverting pregnant women without medical needs to primary health care institutions are main issues that need to be considered.

Our study also suggests that convenience may be an important part of women's choice of hospital. Attendance at a tertiary vs a primary hospital was associated with women choose public transport/taxi as their mode of transport (compared with on foot). In China, these are also the main modes of transport mode in urban areas, where the tertiary hospitals are located. These factors demonstrate that patients in rural areas may find access to specialist medical attention to be more difficult, and this should be a consideration when defining future healthcare investment and policy. Long waiting times in tertiary hospitals is also an ongoing challenge for the national health service [36-38]. 
This research is limited in that it only analyzed selected, pre-defined, environmental and demographic/ pregnancy characteristics. Other factors may also be important, but were not surveyed. As this is a crosssectional study, the results may infected by respondent bias. The interplay between the factors in individual patients could not be assessed due to the nature of the analysis.

\section{Conclusion}

One environmental factor (urban vs rural living), and several demographic/pregnancy characteristics (a planned pregnancy, history of a complicated pregnancy, perceived necessity for maternal healthcare, number of prior abortions, woman's age, highest education level, distance to the hospital, waiting time, mode of transport, power to make decision about delivery location) were found to be associated with pregnant women's choice of hospital in Guangdong, China. To optimize the efficiency of the national health service, we have an idea that women with low risk pregnancies should be initially encouraged to attend a primary or secondary hospital for antenatal care, which could relieve the pressure on resources in tertiary hospitals. Of course, there are lots of tasks such as the safety, cost and efficiency of care delivered at various sites should be studied in future researches.

\section{Acknowledgements}

The authors gratefully acknowledge to pregnant women who participate in the survey.

\section{Authors' contributions \\ GHL and YLX conducted calculations, analyzed results, drafted the manuscript, and contributed equally to this work. YBY, QSG and XW were responsible for the overall design of the research, organized and conducted the survey, and designed the analyses framework. ZZQ, and YNY assisted with the literature review and data collection. All authors approval of the current version of this manuscript for publications.}

\section{Funding}

This study was supported by the Science and Technology Planning Project of Guangdong Province of China [Grant No.2017ZC0276], Medical Scientific Research Foundation of Guangdong Province of China [Grant No.A2019509], Key R \& D and Planning projects of the Ministry of Science and Technology [Grant No.2018YFC2001805].

\section{Availability of data and materials}

All the data relevant for the manuscript are reported in tables. The raw data can be accessed from the corresponding author up on request.

\section{Ethics approval and consent to participate}

Our study was approved by the ethics committee of Guangdong Provincial People's Hospital.

\section{Consent for publication}

Not applicable.

\section{Competing interests}

The authors declare that they have no competing interests.

\section{Author details}

'Guangdong Provincial People's Hospital, Guangdong Academy of Medical Sciences, 106 Zhongshan II Yuexiu District, Guangzhou, Guangdong, China. ${ }^{2}$ Southern Medical University, 1023-1063 Shatai south road, Guangzhou, Guangdong, China. ${ }^{3}$ College of Humanities and Social Sciences, China Medical University, 77 Puhe Road, Shenbei New District, Shenyang, Liaoning, China. ${ }^{4}$ Guangdong Medical University, Songshan lake science and technology industrial park, Dongguan, Guangdong, China.

Received: 18 May 2019 Accepted: 13 August 2019

Published online: 19 August 2019

\section{References}

1. Feijen-de Jong El, Jansen DE, Baarveld F, Boerleider AW, Spelten E, Schellevis F, Reijneveld SA. Determinants of prenatal health care utilisation by low-risk women: a prospective cohort study. Women Birth. 2015;28:87-94.

2. Pang YL. Analysis and prediction of mortality rates for maternal. Weifang Medical College: Infant and Children under five years; 2016.

3. Raatikainen K, Heiskanen N, Heinonen S. Under-attending free antenatal care is associated with adverse pregnancy outcomes. BMC Public Health. 2007;7:268.

4. Hossen A, Ahmmed F. Where do they go, whom do they consult and why? Health seeking behaviors of pregnant women among fishermen Community in Rural Sylhet. International Journal of Social Work \& Human Services Practice. 2015;3:90-9.

5. Loue S. Handbook of immigrant health, 1 edn. New York: Springer science + business media, LLC; 2013. 6.

6. Sreeramareddy CT, Shankar RP, Sreekumaran BV, Subba SH, Joshi HS, Ramachandran U. Care seeking behaviour for childhood illness-a questionnaire survey in western Nepal. BMC Int Health Hum Rights. 2006;6:7.

7. Ferdous F, Das SK, Ahmed S, Farzana FD, Kaur G, et al. The impact of socioeconomic conditions and clinical characteristics on improving childhood care seeking behaviours for families for families living far from the health facility. Science Journal of Public Health. 2013;1:69-76.

8. Boerleider AW, Wiegers TA, Manniën J, Francke AL, Devillé WL. Factors affecting the use of prenatal care by non-western women in industrialized western countries: a systematic review. BMC Pregnancy Childbirth. 2013;13:81.

9. Beeckman K, Louckx F, Putman K. Predisposing, enabling and pregnancyrelated determinants of late initiation of prenatal care. Matern Child Health J. 2011;15:1067-75.

10. Andersen R. Revisiting the behavioral model and access to medical care: does it matter? J Health Soc Behav. 1995:36:1-10.

11. Derose K, Gresenz C, Ringel J. Understanding disparities in health care access--and reducing them--through a focus on public health. Health Aff (Millwood). 2011;30:1844-51.

12. Andersen R, Newman JF. Societal and individual determinants of medical care utilization in the United States. Milbank Mem Fund Q Health Socc. 1973;51:95-124.

13. Liu L, Johnson HL, Cousens S, Perin J, Scott S, Lawn JE, Rudan I, Campbell H, Cibulskis R, Li M, Mathers C, Black RE, Child Health Epidemiology Reference Group of WHO and UNICEF. Global, regional, and national causes of child mortality: an updated systematic analysis for 2010 with time trends since 2000. Lancet. 2012:379:2151-61.

14. Liang B, Feng W. Analysis of the equity of maternal and child health service utilization in China during 2010 to 2015. China Health Industry. 2018;15: 164-8.

15. Liu GH, Yang YB, Geng QS, XUE YL. Healthcare-seeking behavior among pregnant and parturient women from medical institutions of Guangzhou:a decision tree-based analysis. Chinese General Practice. 2018;21:2101-5.

16. Dako-Gyeke P, Aikins M, Aryeetey R, McCough L, Adongo PB. The influence of socio-cultural interpretations of pregnancy threats on health-seeking behavior among pregnant women in urban Accra. Ghana BMC Pregnancy Childbirth. 2013;13:211.

17. Atuyambe L, Mirembe F, Annika J, Kirumira EK, Faxelid E. Seeking safety and empathy: adolescent health seeking behavior during pregnancy and early motherhood in Central Uganda. J Adolesc. 2009;32:781-96.

18. Amin R, Shah NM, Becker S. Socioeconomic factors differentiating maternal and child health-seeking behavior in rural Bangladesh: a cross-sectional analysis. Int J Equity Health. 2010;9:9. 
19. Li C, Shi L, Huang J, Qian X, Chen Y. Factors associated with utilization of maternal serum screening for Down syndrome in mainland China: a crosssectional study. BMC Health Serv Res. 2016;16:1-13.

20. Population ranking of guangdong cities, statistical analysis of population data of guangdong cities in 2018.http://m.creditsailing.com/ ShuJuXiangGuan/707566.html

21. GDP ranking of guangdong in 2015.http://www.southmoney.com/hkstock ggxinwen/201605/572179.html

22. Liu GH, Yang YB, Geng QS, Xue YL. Establishment of comprehensive evaluation index system for maternal health seeking behavior. Chin J Behav Med \& Brain Sci. 2016:25(1):55-9.

23. Johnson CE, Bush RL, Harman J, Bolin J, Evans Hudnall G, Nguyen AM. Variation in utilization of health Care Services for Rural VA enrollees with mental health-related diagnoses. J Rural Health. 2015;31:244-53.

24. Shan D, Qiu PY, Wu YX, et al. Pregnancy outcomes in women of advanced maternal age: a retrospective cohort study from China. Sci Rep. 2018;8(1): 12239.

25. Grieger JA, Bianco-Miotto T, Grzeskowiak LE, et al. Metabolic syndrome in pregnancy and risk for adverse pregnancy outcomes: a prospective cohort of nulliparous women. PLoS Med. 2018;15:e1002710.

26. Fitzpatrick KE, Tuffnell D, Kurinczuk JJ, Knight M. Pregnancy at very advanced maternal age: a UK population-based cohort study. BJOG,2017; 124(7):1097-1106.

27. Health Commission of Guangdong Province. Implementation of advanced maternal management and clinical treatment in Guangdong province (2016-2018). http://zwgk.gd.gov.cn/006940132/201608/t20160824_669828. html [20190626]

28. Qureshi RN, Sheikh S, Khowaja AR, Hoodbhoy Z, Zaidi S, Sawchuck D, et al. Health care seeking behaviours in pregnancy in rural Sindh, Pakistan: a qualitative study. Reprod Health. 2016;13(1 Supplement):34.

29. Grigg CP, Tracy SK, Schmied V, Monk A, Tracy MB. Women's experiences of transfer from primary maternity unit to tertiary hospital in New Zealand: part of the prospective cohort evaluating maternity units study. BMC Pregnancy Childbirth. 2015;15:339.

30. Yanikkerem E, Ay S, Piro N. Planned and unplanned pregnancy: effects on health practice and depression during pregnancy. J Obstet Gynaecol Res. 2013;39:180-7.

31. Wong EL, Popkin BM, Guilkey DK, Akin JS. Accessibility, quality of care and prenatal care use in the Philippines. Soc Sci Med. 1987:24:927-44.

32. Prusty RK, Buoy S, Kumar P, Pradhan MR. Factors associated with utilization of antenatal care services in Cambodia. J public health 2015; 23:1-14. Antenatal care services in Cambodia. J Public Health. 2015;23:1-14.

33. Story WT, Burgard SA, Lori JR, Taleb F, Ali NA, Hoque DM. Husbands' involvement in delivery care utilization in rural Bangladesh: a qualitative study. BMC Pregnancy Childbirth. 2012;12:28.

34. Story WT, Burgard SA. Couples' reports of household decision-making and the utilization of maternal health services in Bangladesh. Soc Sci Med. 2012; 75:2403-11.

35. Allendorf $K$. The quality of family relationships and use of maternal healthcare services in India. Stud Fam Plan. 2010:41:263-76.

36. Sun J, Lin $\mathrm{Q}$, Zhao P, Zhang $\mathrm{Q}, \mathrm{Xu}$ K, Chen $\mathrm{H}$, et al. Reducing waiting time and raising outpatient satisfaction in a Chinese public tertiary general hospital-an interrupted time series study. BMC Public Health. 2017;17(1):668.

37. Hossen M, Westhues A. The medicine that might kill the patient: structural adjustment and its impacts on health care in Bangladesh. Soc Work Public Health. 2012;27:213-28.

38. DU HY, Jiang H, O K, Chen B, Xu L, Liu SP, Yi JP,. Association of Dietary Pattern during Pregnancy and Gestational Diabetes Mellitus: A Prospective Cohort Study in Northern China. Biomed Environ Sci 2017: 30:887-897.

\section{Publisher's Note}

Springer Nature remains neutral with regard to jurisdictional claims in published maps and institutional affiliations.

Ready to submit your research? Choose BMC and benefit from:

- fast, convenient online submission

- thorough peer review by experienced researchers in your field

- rapid publication on acceptance

- support for research data, including large and complex data types

- gold Open Access which fosters wider collaboration and increased citations

- maximum visibility for your research: over $100 \mathrm{M}$ website views per year

At $\mathrm{BMC}$, research is always in progress.

Learn more biomedcentral.com/submissions 